\title{
Prospective randomized controlled trial comparing inpatient and outpatient Foley catheter cervical ripening
}

\section{Rahana Abdul Rahman}

Pusat Perubatan Universiti Kebangsaan Malaysia https://orcid.org/0000-0003-4161-6461

\section{Azzry Mohamad}

Pusat Perubatan Universiti Kebangsaan Malaysia

\section{Aida Hani Mohd Kalok}

Pusat Perubatan Universiti Kebangsaan Malaysia

Nor Azlin Mohamed Ismail

Pusat Perubatan Universiti Kebangsaan Malaysia

\section{Norsaadah Salim}

Pusat Perubatan Universiti Kebangsaan Malaysia

Shuhaila Ahmad ( $\sim$ shuhaila@ppukm.ukm.edu.my)

Pusat Perubatan Universiti Kebangsaan Malaysia https://orcid.org/0000-0003-3722-3948

Research article

Keywords: cervical ripening, Foley catheter, satisfaction

Posted Date: July 24th, 2020

DOI: https://doi.org/10.21203/rs.3.rs-39835/v1

License: (c) (i) This work is licensed under a Creative Commons Attribution 4.0 International License. Read Full License 


\section{Abstract \\ Background}

To evaluate the safety of Foley catheter cervical ripening and patients' satisfaction in outpatient versus inpatient setting.

\section{Methods}

Sixty low risk women were randomized to outpatient $(n=25)$ and inpatient $(n=35)$ cervical ripening using Foley catheter. In both groups Foley catheter with $60 \mathrm{ml}$ balloon was digitally inserted through the cervix with gentle traction applied. The outpatient group was discharged home after provision of verbal and written 24-hours contact information and instructions. The inpatient group was admitted to the ward. They were reassessed the next morning unless labor had begun or the catheter had dropped off.

\section{Results}

The demographic data between the two groups did not differ. The outpatient group has significant improvement in the Bishop score at second assessment (9.04 versus 7.89, $p=0.04$ ), reduced duration of inpatient stay ( 41 versus $59, p<0.001$ ), able to sleep $5-6$ hours ( 9 versus $1, p=0.001$ ), able to rest (23 versus $16, p=0.001)$ and relax (23 versus $10, p<0.001)$. Significantly, more women in the inpatient group had wished to be in the outpatient group ( 3 versus $21, p<0.001$ ). There was no difference in initial Bishop score, duration of oxytocin infusion and delivery within 24 hours. Both groups were similar in caesarean section rate, total blood loss, maternal and neonatal infection, primary postpartum hemorrhage, neonatal birthweight and cord $\mathrm{pH}$. There was no incidence of uterine hyperstimulation, meconium aspiration syndrome and neonatal intensive care unit admission.

\section{Conclusion}

Outpatient Foley catheter cervical ripening had comparable efficacy and safety with inpatient for low-risk pregnancies and associated with better patient satisfaction.

\section{Trial registration:}

NCT04342741. It was retrospectively registered with ClinicalTrial.gov

\section{Background}

Over the past several decades, the practice of inducing labor to shorten the duration of pregnancy had continued to rise. Generally, the rate of labor induction is about $20-30 \%$ of all pregnancies (1). In majority 
of women, labor starts spontaneously resulting in vaginal delivery at or near term. However, due to medical or obstetric complications, induction of labor is often necessary particularly when continuing pregnancy confers a risk to either the mother or the fetus.

Cervical ripening is necessary for women with unfavorable cervix during labor induction. Unfavorable cervix is associated with longer duration of labor and higher rate of failure, requiring an emergency caesarean delivery. Performing pre-induction cervical ripening improves the success rate of labor induction (2). There are various methods available and ideally, it should be effective, safe with minimal side effects to mother and fetus, cheap, easy storage, stable at room temperature and associated with high patient's satisfaction. Prostaglandin E2 had been used for cervical ripening since 1970s. Initially it was administered orally but later was found to be more effective when given intravaginal or intracervical $(2,3)$. However, they are costly, requiring admission with undesirable side effects, particularly uterine hyperstimulation resulting in fetal distress (4).

In 1967 a new method of labor induction had been explored (5). Foley catheter seemed to fulfil the ideal criteria as compared to prostaglandin E2. It was equally effective but with reduced incidence of uterine hyperstimulation, abnormal fetal heart rate changes and cheap (6-8). In most centres, induction of labor was performed in the ward regardless of the method used including Foley catheter insertion. However, due to the reduced associated side effects, labor induction in outpatient setting may be a valid option for the patients. Additionally, the social advantages for patients were evident. Despite this, there were patients who returned to the hospital due to anxiety from having to care for the catheter $(9,10)$. Therefore, the objective of this study was to assess the pregnancy outcomes and patients' satisfaction in outpatient as compared to inpatient cervical ripening with Foley catheter in our centre. The results of this study can be used to change our practice of labor induction.

\section{Methods}

\section{Protocol}

This study adheres to CONSORT guidelines. This was a non-blinded, randomized study which was conducted in Universiti Kebangsaan Malaysia Medical Centre (UKMMC) from 1st August 2017 until 31st May 2018. In our centre, all women who underwent IOL were admitted a day prior regardless of the method used. During this trial, eligible women were recruited after screened in the obstetrics and gynaecology admission centre (OGAC). The inclusion criteria were single fetus, gestational age beyond 37 weeks, cephalic presentation, intact membranes, Bishop score less than 6, age more than 18 years old, lives within $10 \mathrm{~km}$ from UKMMC or able to reach the hospital within 30 minutes with readily available transportation to the hospital. The exclusion criteria were intrauterine death, intrauterine growth restriction, estimated fetal weight $>4000$ gram, fetal anomalies, abnormal pre-induction cardiotocograph, non-vertex presentation, unstable lie, multiple pregnancy, sepsis, hypertension, allergic to latex, had uterine scar, history of antepartum hemorrhage, parity more than six, suspected cephalo-pelvic disproportion and placenta previa. 
The patients were recruited and given full explanation (Fig. 1). Upon obtaining their consents, the patients were randomized using computer generated random numbers (Excel Microsoft software) by the researchers. The initial assessment was performed by the attending doctor which included abdominal and vaginal examination to determine the fetal head engagement and first Bishop score. Blood was withdrawn to determine the baseline hemoglobin level. A 20-minute cardiotocography was performed and if reassuring, a $16 \mathrm{~F}$ or $18 \mathrm{~F}$ latex Foley catheter was inserted into the endocervical canal digitally and advanced past the internal os. The balloon was inflated with $60 \mathrm{ml}$ distilled water. A gentle traction was applied and the catheter was taped to the medial aspect of the thigh.

Women who were randomized to the outpatient group were assessed in the daycare, given written instruction, and provided with oral Tramadol as analgesia to be taken whenever needed and 24 hours contact information for any questions or concerns. The participants were counseled regarding possible discomfort, pain relief, and probability for the balloon to fall out. They were instructed to return immediately to hospital if there were vaginal bleeding, severe abdominal pain, fever, leaking liquor or decreased fetal movements. Otherwise, they were admitted the next morning (12 to 24 hours post catheter insertion), unless labor had started or there were any concerns. In the inpatient group, women were admitted into the ward and Foley catheter was inserted on the same day. They were reviewed the next morning (12 to 24 hours post catheter insertion) or earlier if regular contractions had started.

In both groups, second assessment of the Bishop score was performed following spontaneous expulsion of the balloon or the next morning. If the Bishop score improved to 6 or more, amniotomy was performed. Oxytocin infusion was commenced if the contractions were not optimized. If the Bishop score remained less than 6 cervical ripening was continued using $3 \mathrm{mg}$ intravaginal prostaglandin E2 (PGE2). The details of intrapartum and postpartum management, maternal and fetal outcomes and patients' satisfaction were recorded and analyzed.

After delivery, the participants answered a questionnaire regarding their experience during cervical ripening using Foley catheter. A 5-point Likert scale response format was used. Additional questions were formatted as free text responses exploring opinions on labor induction using Foley catheter and views on steps to improve the outpatient management in order to maintain the practice. The questionnaire had been validated via internal consistency test with Cronbach Alpha's score of 0.714 .

\section{Outcomes}

The primary outcomes assessed were caesarean section rate, neonatal sepsis based on serum white cell count and C-reactive protein and feeling lonely. Secondary outcomes assessed were time from induction to delivery, delivery within 24 hours, duration of inpatient stay, total blood loss, intrapartum pyrexia, primary postpartum hemorrhage, neonatal birth weight, arterial cord $\mathrm{pH}$, meconium aspiration syndrome and admission to the neonatal intensive care unit (NICU).

\section{Sample size calculation}

We used the endpoint of feeling emotionally alone during ripening by Wilkinson et al (9) as it indicated that the rate of feeling emotionally alone during cervical ripening was $10 \%$ and $40 \%$ among the outpatient and 
inpatient group respectively. The calculated Standardized Difference was 0.7. The required sample size estimated using nomogram by Altman, 1982 was 30 for each arm to be able to reject the null hypothesis with probability (power) $0.8 \%(11)$. We then added $10 \%$ of the additional sample for any bias or loss of data during follow up which concluded our sample size to 66 samples. Therefore 33 women would be required in each group to demonstrate a significant difference. The Type I error probability associated with this test of this null hypothesis is 0.05 .

\section{Statistical analysis}

All results were analysed using the Statistical Package for Social Sciences for Windows (SPSS Version 23). Normality of numerical data was assessed using Kolmogorov-Smirnov analysis. Normally distributed continuous variables were assessed using Student's t-test and expressed as mean (SD). Non-normally distributed continuous variables were assessed using Mann-Whitney test and expressed as median (IQR). For dichotomous data, results were analyzed using Chi-square test or Fisher exact test where ever appropriate. Statistical significance was defined as $p$ value $<0.05$.

\section{Results}

A total of 110 women were screened at enrolment. Only 60 of them fulfilled the criteria and randomized into 2 groups. Due to the time constraint and patients' anxiety in the outpatient arm, total recruitment was 25 women in the outpatient group and 35 women in the inpatient group (Table 1). The demographic characteristics of the two groups were similar at trial entry, and it was reflective of the patients' cohort which consisted predominantly of professionals with higher academic qualifications. Majority were multiparous Malay women who were overweight with similar mean gestational age in both groups. Postterm pregnancy and gestational diabetes mellitus (GDM) on diet modification were the commonest indication for IOL. 
Table 1

Demographic data of study population $(n=60)$

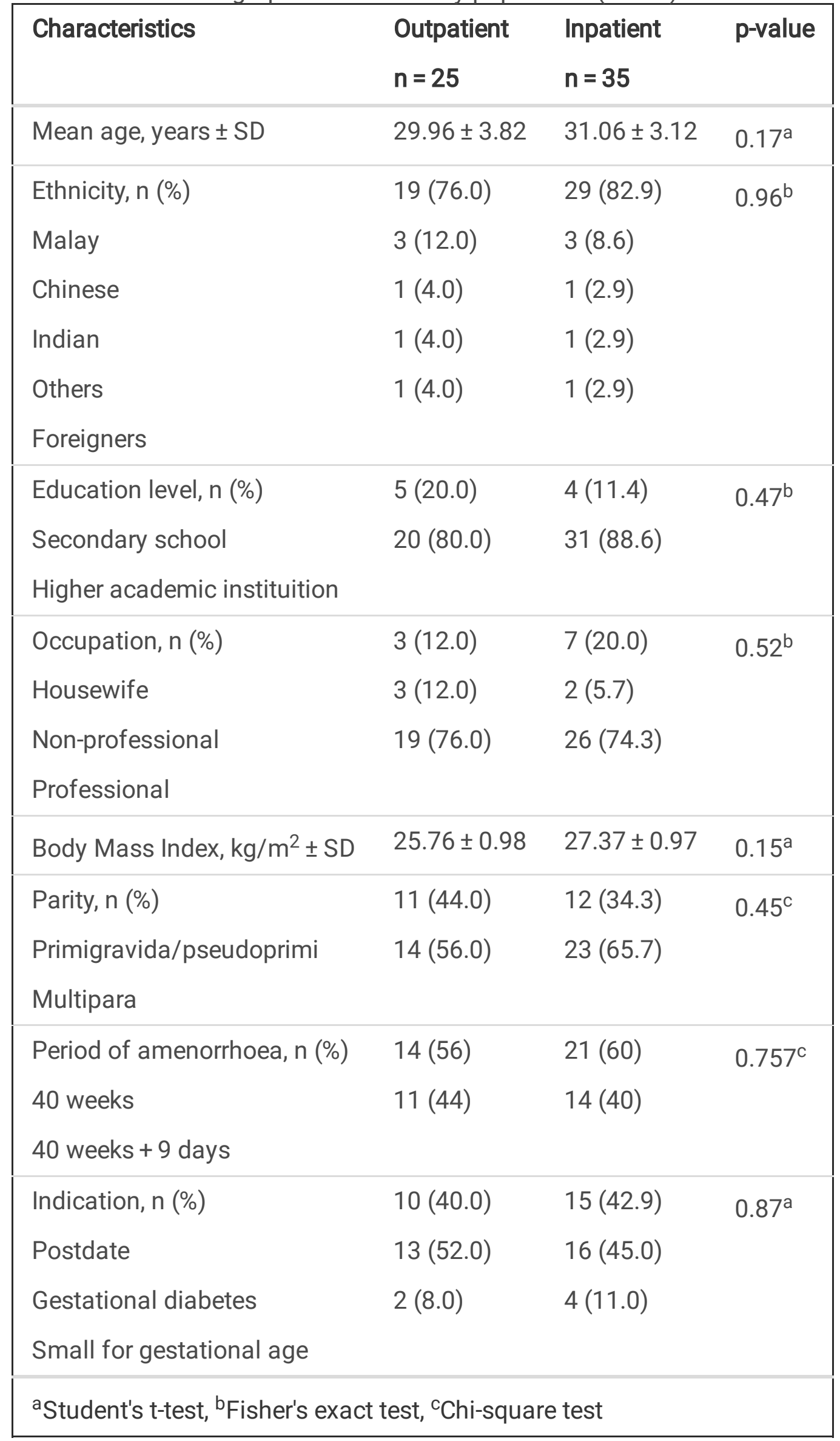




\section{Details of management}

Although the mean baseline Bishop score was similar between the two groups (Table 2), at the second assessment the outpatient group had significant improvement (9.04 vs $7.89, p=0.04$ ). Consequently, the duration taken to ripen the cervix after admission was significantly shorter with outpatient management ( 0.83 vs $19.5, p<0.001)$ due to the more favorable cervix during the second assessment leading to significantly shorter hospital stay (41 vs $59, p<0.001)$. More women in the inpatient group required further cervical ripening with prostaglandin $E_{2}\left(P E_{2}\right)$ pessary but was not statistically significant $(p=0.63)$. Both groups were similar in the need for further oxytocin augmentation, duration of its infusion and delivery within 24 hours.

Table 2

Clinical characteristics of study population $(n=60)$

\begin{tabular}{|c|c|c|c|}
\hline Variables & $\begin{array}{l}\text { Outpatient } \\
n=25\end{array}$ & $\begin{array}{l}\text { Inpatient } \\
\mathrm{n}=35\end{array}$ & $\begin{array}{l}\text { p- } \\
\text { value }\end{array}$ \\
\hline Bishop score, mean \pm SD & $3.68 \pm 0.48$ & $3.57 \pm 0.70$ & $0.50^{\mathrm{b}}$ \\
\hline Pre-induction & $9.04 \pm 1.70$ & $7.89 \pm 2.26$ & $0.04^{\mathrm{b}}$ \\
\hline \multicolumn{4}{|l|}{ Second assessment } \\
\hline Management after second assessment, $\mathrm{n}(\%)$ & $24(96.0)$ & $32(91.4)$ & $0.63^{\mathrm{a}}$ \\
\hline $\begin{array}{l}\text { ARM } \\
\text { dinoprostone insertion }\end{array}$ & $1(4.0)$ & $3(8.6)$ & $0.63^{\mathrm{a}}$ \\
\hline $\begin{array}{l}\text { Duration from induction to favorable Bishop score } \\
\text { (hours), median (IQR) }\end{array}$ & $\begin{array}{l}19.75(17.04- \\
24.40)\end{array}$ & $\begin{array}{l}19.67(15.17- \\
22.50)\end{array}$ & $0.81^{\mathrm{c}}$ \\
\hline Augmentation with oxytocin, n (\%) & $18(72.0)$ & $25(71.4)$ & $0.96^{\mathrm{d}}$ \\
\hline Duration of oxytocin use (minutes), median (IQR) & $\begin{array}{l}150(0.0- \\
345.0)\end{array}$ & $\begin{array}{l}210(0.0- \\
300.0)\end{array}$ & $0.67^{b}$ \\
\hline $\begin{array}{l}\text { Duration from amniotomy to delivery, mean (hours) } \pm \\
\text { SD }\end{array}$ & $5.99 \pm 3.30$ & $6.81 \pm 3.43$ & $0.33^{b}$ \\
\hline Duration from induction to delivery, mean (hours) \pm SD & $24.97 \pm 6.63$ & $26.29 \pm 6.20$ & $0.43^{\mathrm{b}}$ \\
\hline Delivery within 24 hours, $n(\%)$ & $9(36.0)$ & $12(34.3)$ & $0.89^{\mathrm{a}}$ \\
\hline Duration of inpatient stay, mean (hours) \pm SD & $41.0 \pm 15.0$ & $59 \pm 16.0$ & $\begin{array}{l}< \\
0.001^{\mathrm{b}}\end{array}$ \\
\hline
\end{tabular}

\section{Maternal and neonatal outcome}


There were no significant differences in maternal and neonatal outcomes between the two groups (Table 3). Majority had successful vaginal delivery with more women in the inpatient group had caesarean section but was not statistically significant $(28.6 \%$ vs $12.0 \%, p=0.204)$. The main indications for caesarean section were fetal distress and poor progress. No serious maternal and neonatal complications were encountered during the study such as meconium aspiration syndrome or NICU admission (results not shown). A total of three patients experienced intrapartum pyrexia and received intravenous antibiotics. The fever subsided immediately after delivery and the recovery period in the ward was uneventful. Neonatal assessment by the pediatric team revealed healthy babies with normal levels of total white blood cell counts and C-reactive protein. Three patients had primary postpartum hemorrhage due to uterine atony with blood loss ranged between 500 to $800 \mathrm{mls}$. The drop in hemoglobin levels were 1.5 to $2.0 \mathrm{~g} / \mathrm{dL}$ and none of them required blood transfusion.

Table 3

Pregnancy outcomes of study population $(n=60)$

\begin{tabular}{|c|c|c|c|}
\hline Variables & $\begin{array}{l}\text { Outpatient } \\
n=25\end{array}$ & $\begin{array}{l}\text { Inpatient } \\
\mathrm{n}=35\end{array}$ & p-value \\
\hline Mode of delivery, $\mathrm{n}(\%)$ & $21(84.0)$ & $22(62.9)$ & $0.22^{d}$ \\
\hline Spontaneous vaginal & $1(4.0)$ & $3(8.6)$ & \multirow{2}{*}{$0.07^{d}$} \\
\hline Instrumental & $3(12.0)$ & $10(28.6)$ & \\
\hline Caesarean & $1(33.3)$ & $3(30.0)$ & $0.64^{a}$ \\
\hline Fetal distress & $2(66.7)$ & $7(70.0)$ & \multirow{2}{*}{$0.20^{\mathrm{a}}$} \\
\hline \multicolumn{3}{|l|}{ Abnormal labor progress } & \\
\hline Total blood loss (ml), median (IQR) & $300(200-300)$ & $300(250-300)$ & $0.68^{\mathrm{c}}$ \\
\hline Intrapartum pyrexia, n (\%) & $2(8.0)$ & $1(2.9)$ & $0.37^{d}$ \\
\hline Primary postpartum hemorrhage, $\mathrm{n}(\%)$ & $1(4.0)$ & $2(5.7)$ & $0.76^{d}$ \\
\hline Birth weight, mean $($ gram $) \pm S D$ & $3208 \pm 286.6$ & $3030 \pm 442.5$ & $0.06^{\mathrm{b}}$ \\
\hline Arterial cord $\mathrm{pH}$, mean $\pm \mathrm{SD}$ & $7.34 \pm 0.48$ & $7.31 \pm 0.51$ & $0.08^{\mathrm{b}}$ \\
\hline Neonatal blood investigation & $18.71 \pm 5.38$ & $16.64 \pm 3.24$ & $0.09^{b}$ \\
\hline White cell count, mean \pm SD & $0.02(0.02-0.04)$ & $0.03(0.02-0.08)$ & $0.19^{c}$ \\
\hline C-reactive protein, median (IQR) & & & \\
\hline
\end{tabular}

\section{Women satisfaction}


Majority of women ( $64 \%$ vs $57.1 \%, p=0.711)$ agreed or strongly agreed that the insertion of the catheter was most uncomfortable during insertion, but most of them were able to cope with the discomfort (Table 4). However, only about a quarter of patients felt significant discomfort throughout IOL ( $12 \%$ vs $14.4 \%, p=0.892$ ). Significantly more women in the outpatient group reported less feeling of loneliness ( $8 \%$ vs $40 \%, p=0.021$ ) and most were able to rest and relax. The sleep quantity of 5-6 hours was significantly greater in the outpatient group ( $36 \%$ vs $2.9 \%, p=0.001)$ as compared to $3-4$ hours in the inpatient group. Women in the outpatient group in general did not have any concern regarding the safety of going through induction of labor at home. Five patients (20\%) sought advice via phone call regarding passing out mucus discharge and were happy to remain at home until the next morning or when the catheter had dropped. Overall, most of them were keen to choose this method of induction again. Those in the inpatient group $(60 \%)$ expressed their wishes to be in the outpatient group in future. 
Table 4

Patients' satisfaction survey, $\mathrm{n}=60$

\begin{tabular}{|llll|}
\hline Variables & Outpatient & Inpatient & p-value \\
& $\mathbf{n = 2 5}$ & $\mathbf{n = 3 5}$ & \\
\hline Discomfort with Foley catheter, & $16(64.0)$ & $20(57.1)$ & $0.71^{\mathrm{a}}$ \\
$\mathrm{n}(\%)$ & $10(40.0)$ & $7(20.0)$ & $0.25^{\mathrm{a}}$ \\
At insertion & $3(12.0)$ & $5(14.3)$ & $0.89^{\mathrm{a}}$ \\
4 to 6 hours & & & \\
Overall & & & \\
\hline Able to cope with discomfort, & $23(92.0)$ & $26(74.3)$ & $0.24^{\mathrm{a}}$ \\
$\mathrm{n}$ (\%) & $22(88.0)$ & $29(82.9)$ & $0.85^{\mathrm{a}}$ \\
At insertion & $22(88.0)$ & $32(91.4)$ & $0.81^{\mathrm{a}}$ \\
4 to 6 hours & & & \\
Overall & & & \\
\hline Would choose this method again, $\mathrm{n}(\%)$ & $20(80.0)$ & $26(74.3)$ & $0.34^{\mathrm{a}}$ \\
\hline Feeling alone during induction, & $2(8.0)$ & $14(40.0)$ & $0.02^{\mathrm{b}}$ \\
$\mathrm{n}$ (\%) & $1(4.0)$ & $1(2.9)$ & $0.81^{\mathrm{b}}$ \\
Agreed/ Strongly agreed & $22(88.0)$ & $20(57.1)$ & $0.01^{\mathrm{b}}$ \\
Unsure & & & \\
Disagreed/ Strongly disagreed & & & \\
\hline
\end{tabular}

${ }^{a}$ Fisher's exact test, ${ }^{b}$ Chi square test 


\begin{tabular}{|c|c|c|c|}
\hline Variables & $\begin{array}{l}\text { Outpatient } \\
n=25\end{array}$ & $\begin{array}{l}\text { Inpatient } \\
\mathrm{n}=35\end{array}$ & p-value \\
\hline Duration of sleep, $\mathrm{n}(\%)$ & $2(8.0)$ & $5(14.3)$ & \multirow[t]{5}{*}{$0.001^{\mathrm{a}}$} \\
\hline Less than 1 hour & $4(16.0)$ & $14(40.0)$ & \\
\hline 1 to 2 hours & $7(28.0)$ & $15(42.9)$ & \\
\hline 3 to 4 hours & $9(36.0)$ & $1(2.9)$ & \\
\hline 5 to 6 hours & $3(12.0)$ & $0(0)$ & \\
\hline \multirow[t]{4}{*}{ More than 6 hours } & & & $a 05 b$ \\
\hline & & & $0.24^{\mathrm{b}}$ \\
\hline & & & $0.001^{b}$ \\
\hline & & & $0.04^{\mathrm{b}}$ \\
\hline Able to rest, $\mathrm{n}(\%)$ & $23(92.0)$ & $16(45.7)$ & $0.001^{a}$ \\
\hline Able to relax, n (\%) & $23(92.0)$ & $10(28.6)$ & $<0.001^{\mathrm{a}}$ \\
\hline $\begin{array}{l}\text { Worried that IOL is not safe, } \\
n(\%)\end{array}$ & $3(12.0)$ & $4(11.4)$ & $0.75^{a}$ \\
\hline $\begin{array}{l}\text { Wished to be in the other group, } \\
n(\%)\end{array}$ & $3(12.0)$ & $21(60.0)$ & $<0.001^{\mathrm{a}}$ \\
\hline $\begin{array}{l}\text { Embarassed by the method used, } \\
\mathrm{n}(\%)\end{array}$ & $4(16.0)$ & $4(11.4)$ & $0.32^{\mathrm{a}}$ \\
\hline${ }^{\mathrm{a}}$ Fisher's exact test, ${ }^{\mathrm{b}} \mathrm{Chi}$ square test & & & \\
\hline
\end{tabular}

\section{Discussion}

The efficacy of Foley catheter as cervical ripening agent had been proven to be similar to the prostaglandin E2 in the inpatient setting. The caesarean delivery rate, duration from induction to delivery and failed cervical ripening within 12-24 hours were comparable. Likewise, the safety of Foley catheter was clearly demonstrable as it was less associated with uterine hypertonus with no significant adverse events such as maternal or neonatal infection, morbidities and mortalities. However, understandably the use of oxytocin infusion was significantly more (12). The overall oxytocin use in this study was $72 \%$ but there was a non significant shorter median time on oxytocin infusion in the outpatient group. This could be due to small sample size from this study. 
To date, there were limited published data comparing the use of Foley catheter between inpatient and outpatient setting. The use of Foley catheter for cervical ripening did not result in significant improvement in the Bishop score. This was in contrast to our study whereby the improvement was significant in the outpatient group $(13,14)$. The reason was unclear as the initial Bishop score was similar in all these studies. The outpatient group required significantly shorter duration of hospital stay which concurred with study by Wilkinson et al. and Policiano et al. as a result of later admission and higher Bishop score in the second assessment $(13,14)$. Additionally, there were no cases of born-before arrival which is consistent with other studies $(9,14,15)$.

In this study, only about a third of women in the two groups delivered within 24 hours of induction which was consistent with other catheter ripening studies $(10,15)$. We did not follow a strict time-based protocol, but rather women were assessed for amniotomy the morning following the ripening process that occurred overnight. In both groups, the average duration of a catheter in situ was 19 hours. This was higher from the study by Wilkinson et al. as our patients came for assessment between $12-5 \mathrm{pm}$, followed by second assessment at 7-8 am the coming morning, unless the onset of labor had begun. In the outpatient group, we speculated that due to the better home environment and increased patient mobility at home had improved the Bishop score at second assessment significantly.

Our findings suggest that outpatient ripening with Foley catheter may be an option for an appropriately screened women with low-risk pregnancies. The safety of Foley catheter cervical ripening was apparent as there were neither NICU admission nor meconium aspiration syndrome and there was no significant difference in the incidence of neonatal sepsis. Not surprisingly, the caesarean delivery rate was similar between the two groups which were in agreement with the previous published studies (12-14). However, one study showed significantly higher rate of caesarean section due to failed labor induction in the outpatient group (13).

Most of the women in both groups found the catheter was uncomfortable at the time of insertion. We used digital insertion during a vaginal examination to all of our patients as a study found that insertion using speculum had higher pain scores compared to digital insertion (16). Although the discomfort with the Foley catheter was the same in both groups, the outpatient group was less lonely during the labor induction. Apart from that, they enjoyed longer duration of sleep, rest and relax. These were all in line with previous studies (9). Hence, there was significant number of inpatient who wished to have the procedure as outpatient due to all the benefits mentioned earlier. Although the cost was not assessed, it is usually translated by the duration of overnight stay in the ward which would make it most likely cheaper for the outpatient group.

The strength of the study was it is a randomized clinical trial that was designed according to the local setting. Like other preceding studies, the major limitations of the study were its small sample size, involved only a single-center and blinding the clinician to the group was not possible. The costs of both groups would have been beneficial.

\section{Conclusion}


The result of this study was encouraging. Although Foley catheter ripening process may be slower than the pharmacological method, the efficacy was comparable to PGE2 and safety between inpatient and outpatient settings was similar. In addition, the total duration of inpatient stay was shorter for the outpatient group. Therefore, outpatient Foley catheter cervical ripening is a valid option in patients who are deemed to be low risk following a careful screening.

\section{Declarations}

\section{Ethics approval}

The study was approved by the local Research Ethics Committee (FF-2017-358). Written consents were obtained from the participants.

\section{Consent for publication}

Not applicable

\section{Availability of data and materials}

The datasets used and/or analysed during the current study are available from the corresponding author on reasonable request.

\section{Competing interest}

The authors declare that they have no competing interests

\section{Funding}

No funding involved

\section{Authors' contribution}

NS produced the idea. AM performed the study, analysed the data and was the major contributor to the writing of the manuscript. SA analysed the data and was the main editor for the manuscript. RAR, AHMK and NMI contributed in editing of the manuscript. All authors have read and approved the manuscript .

\section{Acknowledgments}

The authors would like to thank all the patients who medical personnel who participated directly or indirectly in the study.

\section{References}

1. WHO recommendations for induction of labour. World Health Organization, Dept. of Reproductive Health and Research 2011 [cited 27 March 2019]. Available from: https://www.who.int/reproductivehealth/publications/maternal_perinatal_health/9789241501156/en/. 
2. Steiner H, Zahradnik H, Breckwoldt M, Robrecht D, Hillemanns H. Cervical ripening prior to induction of labour (intracervical application of a PGE2 viscous gel). Prostaglandins. 1979;17(1):125-33.

3. Gabert H, Herbertson R. The use of oral prostaglandin E2 to induce labor at term. J Reprod Med. 1976;16(5):276-80.

4. Lipshitz J, Klose C. Use of tocolytic drugs to reverse oxytocin-induced uterine hypertonus and fetal distress. Obstetrics \& Gynecology. 1985;66(3).

5. Embrey M, Mollison B. The unfavourable cervix and induction of labour using a cervical balloon. J Obstet Gynaec Brit Cwlth. 1967;74:44-8.

6. Dahiya K, Malik K, Dahiya A, Nanda S. Comparison of the Efficacy of Foley Catheter Balloon with Dinoprostone Gel for Cervical Ripening at Term. International Journal of Clinical Medicine. 2012;03(06):527-31.

7. Jozwiak M, Rengerink KO, Benthem M, et al. Foley catheter versus vaginal prostaglandin E2 gel for induction of labour at term (PROBAAT trial): an open-label, randomised controlled trial. The Lancet. 2011;378(9809):2095-103.

8. Heinemann J, Gillen G, Sanchez-Ramos L, Kaunitz AM. Do mechanical methods of cervical ripening increase infectious morbidity? A systematic review. Am J Obstet Gynecol. 2008;199(2):177-88.

9. Wilkinson C, Adelson P, Turnbull D. A comparison of inpatient with outpatient balloon catheter cervical ripening: a pilot randomized controlled trial. BMC Pregnancy Childbirth. 2015;15(1):126.

10. Henry A, Madan A, Reid R, et al. Outpatient Foley catheter versus inpatient prostaglandin E2 gel induction of labour: a randomised trial. BMC Pregnancy Childbirth. 2013;13(25):1-11.

11. Whitley E, Ball J. Statistics review 4: Sample size calculations. Crit Care. 2002;6:335-41.

12. Vaknin Z, Kurzweil Y, Sherman D. Foley catheter balloon vs locally applied prostaglandins for cervical ripening and labor induction. American J of Obstet Gynecol. 2010;203(5):418-29.

13. Policiano C, Pimenta M, Martins D, Clode N. Outpatient versus inpatient cervix priming with Foley catheter: A randomized trial. Eur J Obstet Gynecol Reprod Biol. 2017;210:1-6.

14. Sciscione A, Muench M, Pollock M, Jenkins T, Tildon-Burton J, Colmorgen C. Transcervical Foley catheter for preinduction cervical ripening in an outpatient versus inpatient setting. Obstet Gynecol. 2001;98:751-6.

15. Wilkinson C, Bryce R, Adelson P, Turnbull D. A randomised controlled trial of outpatient compared with inpatient cervical ripening with prostaglandin E2 (OPRA study). BJOG. 2015;122:94-106.

16. Jonsson M, Hellgren C, Wiberg-Itzel E, Akerud H. Assessment of pain in women randomly allocated to speculum or digital insertion of the Foley catheter for induction of labor. Acta Obstet Gynecol Scand. 2011;90:997-1004.

\section{Supplementary Files}

This is a list of supplementary files associated with this preprint. Click to download.

- CONSORTguideline.pdf 